\title{
OSTEOARTROPATIA HIPERTRÓFICA PRIMÁRIA: RELATO DE CASO E REVISÃO DA LITERATURA*
}

\author{
Andréa de Almeida Peduti Batista ${ }^{1}$, José Antônio de Paula Bianco ${ }^{2}$, Adriano Peduti Batista ${ }^{3}$, \\ Luis Renato Alves ${ }^{3}$, Anderson Afonso ${ }^{3}$, Hélder de Souza Lima e Silva ${ }^{4}$, Fabiano de Almeida \\ Borges $^{5}$, Celso Montenegro Turtelli ${ }^{6}$, Marlene Freire ${ }^{7}$
}

\begin{abstract}
Resumo Os autores relatam um caso de osteoartropatia hipertrófica do tipo primária em paciente de 29 anos de idade, com dores articulares e aumento de volume das extremidades há 15 anos. Ao exame físico apresentava baqueteamento dos dedos e unhas em "vidro de relógio". A osteoartropatia hipertrófica foi considerada como primária porque foram excluídas todas as causas da forma secundária. As principais alterações radiológicas foram: espessamento das camadas corticais dos ossos tubulares e reação periosteal contínua do tipo lamelar. Não foram notadas alterações dos espaços articulares.

Unitermos: Osteoartropatia hipertrófica; Paquidermoperiostose; Baqueteamento digital.
\end{abstract}

Abstract Primary hypertrophic osteoarthropathy: a case report and review of the literature.

The authors report a case of primary hypertrophic osteoarthropathy in a 29-year-old male with swollen joints. Physical examination revealed also digital clubbing and convexity of the nails. All other causes of secondary forms of hypertrophic osteoarthropathy were excluded. The main radiological abnormalities found were bone cortical hypertrophy and periosteal proliferation. Abnormalities of the joint spaces were not observed. Key words: Hypertrophic osteoarthropathy; Pachydermoperiostosis; Digital clubbing.

\section{INTRODUÇÃO}

A osteoartropatia hipertrófica primária (OAH) ou paquidermoperiostose é uma síndrome caracterizada por baqueteamento digital, neoformação óssea no periósteo (em 97\% dos casos), especialmente nas diáfises distais dos ossos longos (antebraço e perna), fácies de aspecto áspero, com pele grosseira, enrugada e oleosa na região frontal, cutis verticis gyrata (em 98\% dos casos), "pés de elefante" (em 24\% dos casos) e seborréia (em 33\% dos casos) ${ }^{(1-4)}$. O início da doença tem distribuição bimodal, com um pico no primeiro ano de vida e outro aos 15 anos, coincidindo com o período de crescimento rápido na puberda$\mathrm{de}^{(5)}$. A OAH pode ser classificada em primária, com provável herança autossômica

* Trabalho realizado nas Disciplinas de Reumatologia e de Radiologia do Departamento de Clínica Médica da Faculdade de Medicina do Triângulo Mineiro (FMTM), Uberaba, MG.

1. Médica Residente $\left(R_{3}\right)$ em Reumatologia da FMTM.

2. Médico Residente $\left(R_{2}\right)$ em Reumatologia da FMTM

3. Acadêmicos ( $9^{\circ}$ período) de Medicina da FMTM.

4. Médico Residente $\left(R_{1}\right)$ em Radiologia da FMTM.

5. Médico Residente $\left(R_{3}\right)$ em Radiologia da FMTM.

6. Professor Adjunto da Disciplina de Radiologia da FMTM.

7. Professora Adjunta da Disciplina de Reumatologia da FMTM.

Endereço para correspondência: Prof. Dr. Celso Montenegro

Turtelli. Rua Constituição, 751. Uberaba, MG, 38025-110.

E-mail: celsomt@mednet.com.br

Recebido para publicação em 6/9/2002. Aceito, após revisão, em 6/12/2002. dominante, de penetrância variável, e na forma secundária, como conseqüência de doenças pulmonares crônicas, cardiopatias congênitas cianóticas, doenças hepatobiliares e síndromes paraneoplásicas ${ }^{(6,7)}$.

\section{RELATO DO CASO}

Paciente do sexo masculino, 29 anos de idade, branco, casado, aposentado, natural e procedente de Perdizes, MG, chegou ao ambulatório de Reumatologia com queixa de dores nas juntas há um ano. Referia que há 15 anos vinha apresentando aumento do comprimento e espessura dos dedos das mãos e dos pés, poliartralgia das mãos, pés, joelhos e tornozelos, às vezes acompanhada de edema. Há um ano vem ocorrendo aumento progressivo da dor articular, atualmente contínua, que piora com o esforço e melhora parcialmente com o uso de antiinflamatório não-hormonal. Negava febre, alterações urinárias ou gastrointestinais. No interrogatório complementar referia ter personalidade ansiosa, com história pregressa de picos hipertensivos, encontrando-se, no momento, em uso irregular de anti-hipertensivo. Negava história familiar de alterações semelhantes às dele. Tabagista crônico (quatro cigarros de palha/dia por cinco anos) e etilista por dez anos, tendo abandonado este vício há um ano.

Ao exame físico o paciente encontravase em bom estado geral, afebril, corado e hidratado, com ausculta pulmonar limpa, sem ruídos adventícios e com murmúrio vesicular preservado, bilateralmente. Apresentava coração rítmico a 80 sístoles por minuto, sem sopros e com pressão arterial de $140 \times 80 \mathrm{mmHg}$; abdome sem alterações em relação à normalidade. Apresentava baqueteamento digital em mãos e pés e unhas em "vidro de relógio" (Figuras 1A e 1B), edema de membros inferiores, frio, mole, indolor, cacifo positivo de +/++++, sem dor à palpação e movimentação das articulações, e pés com aspecto de "pés de elefante" (Figura 1B). Havia também aumento do pregueamento cutâneo em região frontal e couro cabeludo, associado a uma maior oleosidade da pele (dermatite seborréica) (Figura 2). Exame neurológico dentro dos padrões da normalidade.

A avaliação laboratorial do paciente mostrou: hemácias, $4.370 .000 / \mathrm{mm}^{3}$; hemoglobina, 14,2 g/dl; hematócrito, 40,5\%; plaquetas, 308.000/ $\mathrm{mm}^{3}$; leucócitos, 5.500/ $\mathrm{mm}^{3}$ (0-61-1-0-36-2). Apresentava velocidade de hemossedimentação de $45 \mathrm{~mm}$ na primeira hora, proteína $\mathrm{C}$ reativa de 3,91 mg/dl, alfa-1 glicoproteína ácida de 


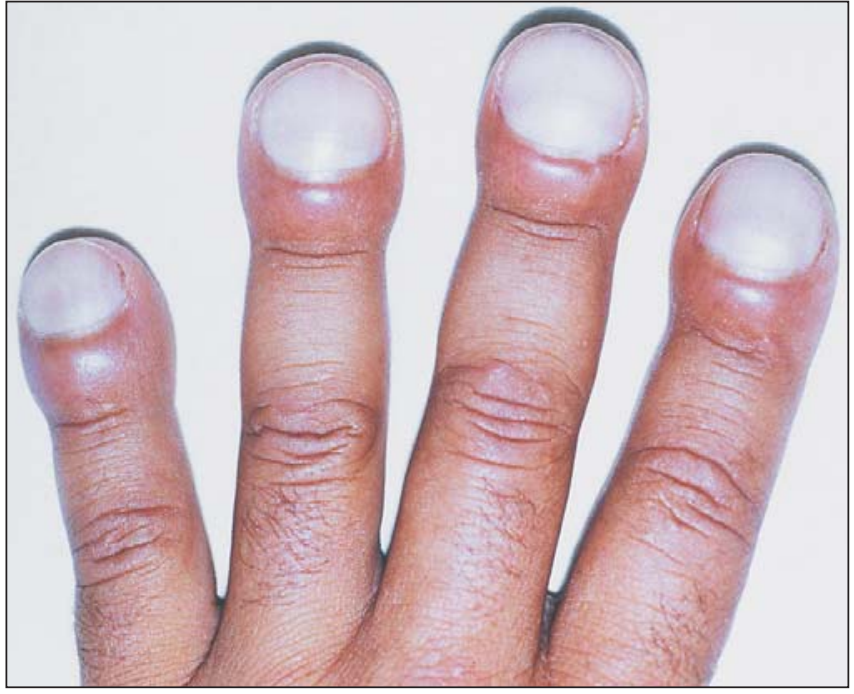

A

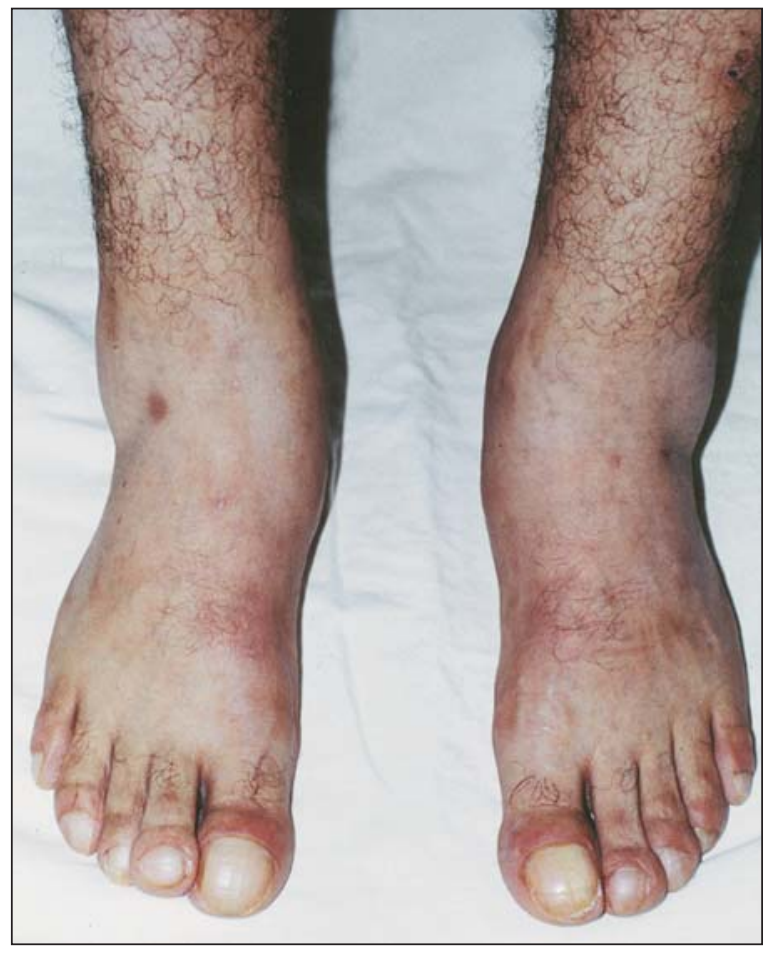

B

Figura 1. Baqueteamento digital em mãos e pés, unhas em "vidro de relógio" (A,B). Edema de membros inferiores, com aspecto de "pés de elefante"(B).

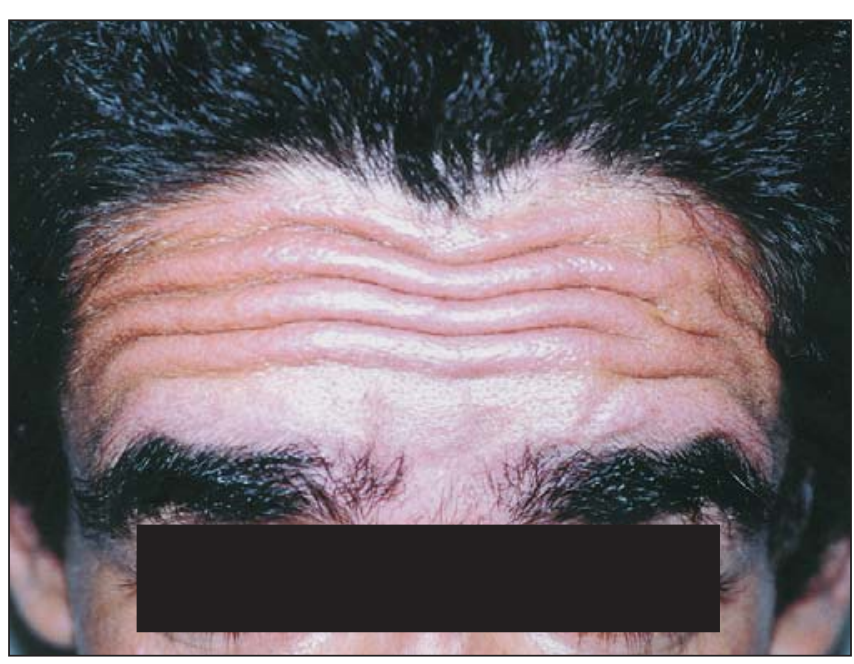

Figura 2. Aumento do pregueamento cutâneo em região frontal e couro cabeludo, associado a maior oleosidade da pele (dermatite seborréica).

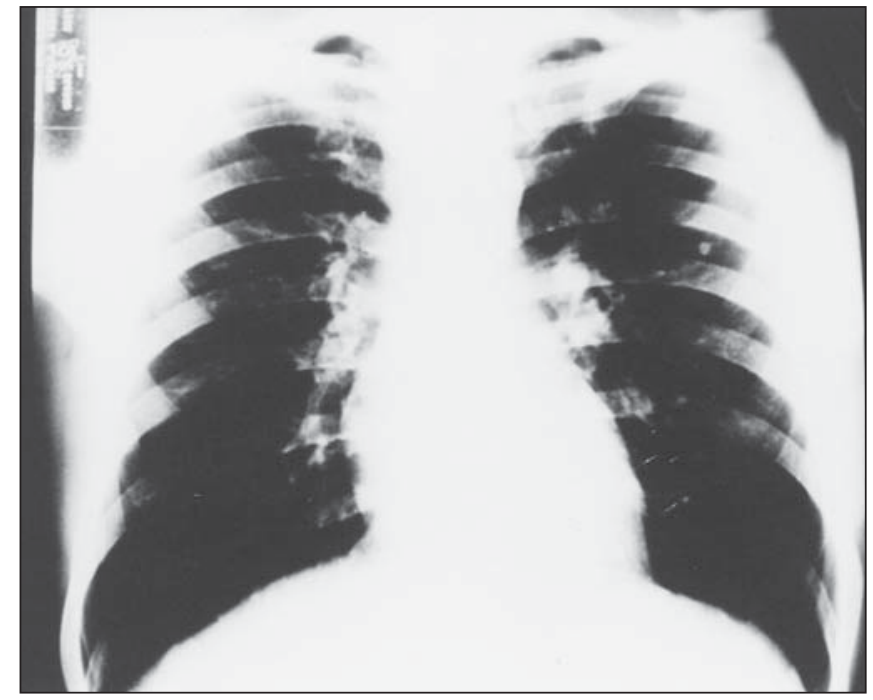

Figura 3. Radiografia de tórax normal.
$124 \mathrm{mg} / \mathrm{dl}$, uréia de $25 \mathrm{mg} / \mathrm{dl}$, creatinina de $1 \mathrm{mg} / \mathrm{dl}$, glicemia de $104 \mathrm{mg} / \mathrm{dl}$, TGO de 17 U/l, TGP de 14 U/l, gama-GT de 11 U/l. Exame de urina normal. Radiografia de tórax normal (Figura 3). Eletrocardiograma com bradiarritmia sinusal e "provável" sobrecarga ventricular esquerda.

A radiografia dos ossos longos mostrou espessamento das camadas corticais com alargamento das diáfises. Notou-se reação periosteal lamelar contínua e espaços articulares conservados (Figuras 4 e 5)

\section{DISCUSSÃO}

A OAH é uma entidade que deve ser diagnosticada precocemente, já que esta enfermidade serve como indicadora de possível afecção grave em outra parte do organismo. É muito raro a OAH surgir sem uma doença primária aparente ${ }^{(3)}$. Ela foi descrita, inicialmente, em dois irmãos, por Friedreich, em 1868. Mais tarde, muitos outros autores reportaram esta afecção ${ }^{(\mathbf{4 , 8 , 9})}$ (Quadro 1). A OAH foi descrita na forma de duas entidades distintas, primária e secundária, atualmente sendo adotada a clas- 

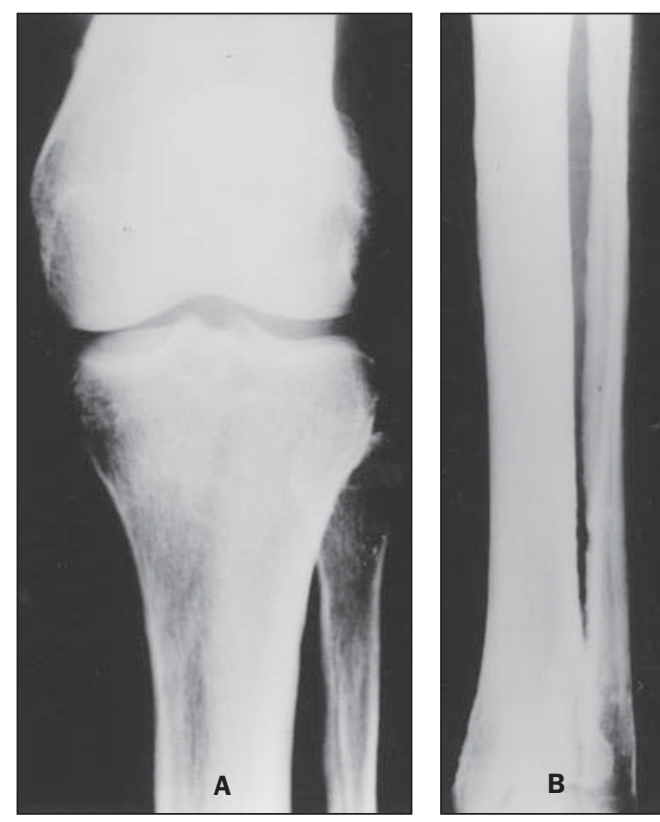

Figura 4. Radiografias mostrando espessamento das camadas corticais, com alargamento das diáfises. Nota-se reação periosteal lamelar contínua e espaços articulares preservados. 0 membro contralateral apresentava os mesmos achados.

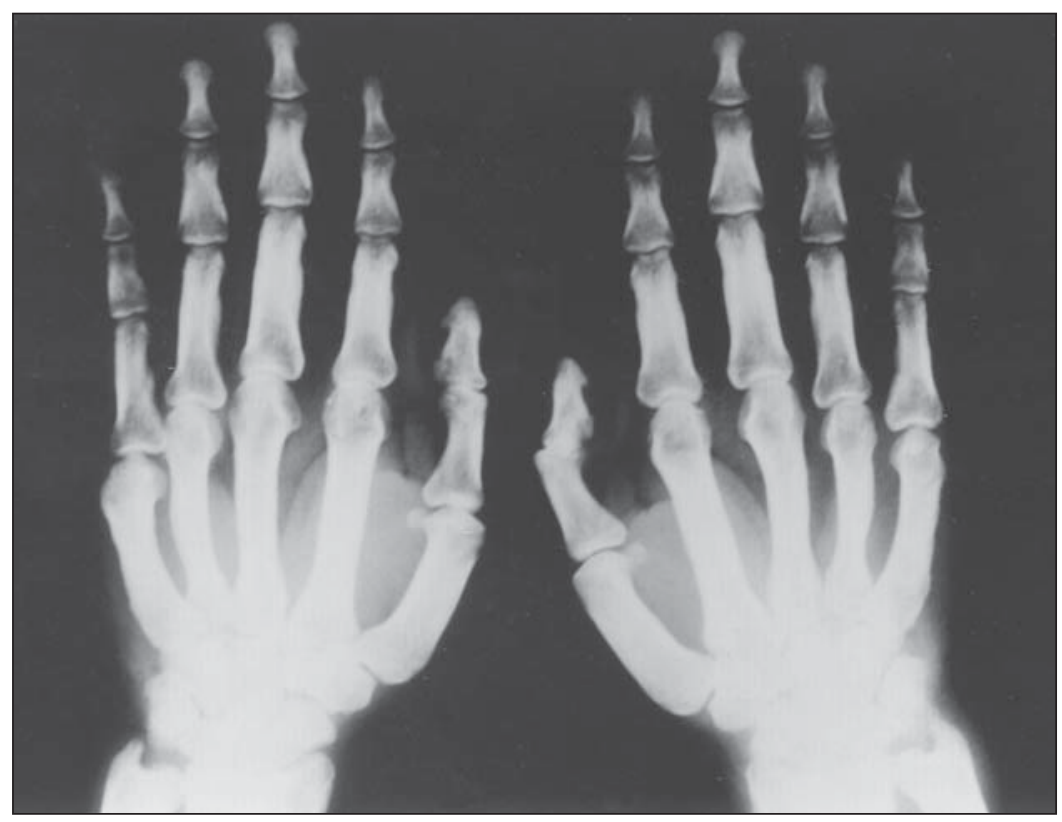

Figura 5. Radiografia das mãos com as mesmas alterações das grafias anteriores.
Quadro 1 Análise histórica e nomenclatura da paquidermoperiostose ${ }^{(8)}$.

\begin{tabular}{|l|l|}
\hline \multicolumn{1}{|c|}{ Autor } & \multicolumn{1}{c|}{ Descrição } \\
\hline Friedreich (1868) & Primeira descrição - hiperostose de todo o esqueleto \\
Gourand (1889) & Segunda descrição - "glosse-pattes” \\
Oehme (1919) & Doença familial acromegalóide do esqueleto \\
Labbé (1926) & Osteodermopatia hipertrófica \\
Grömberg (1927) & Megalia cutis et osseum \\
Mankowsky (1934) & Osteopatia displásica familiar \\
Touraine et al. (1935) & Paquidermia/plicatura com paquiperiostose das extremidades (síndrome de \\
& Touraine-Solente-Golé) \\
Giomo (1937) & Paquidermia com paquiperiostose \\
Uehlinger (1947) & Paquidermia com paquiperiostose \\
Vague (1948) & Paquidermoperiostose \\
Vogi (1962) & Osteoartropatia hipertrófica idiopática \\
\hline
\end{tabular}

sificação proposta por Martínez-Lavin et $a l .{ }^{(\mathbf{1})}$, mostrada no Quadro 2.

A fisiopatologia da paquidermoperiostose ainda é pouco conhecida. Um defeito primário intrínseco das plaquetas, que poderia facilitar a degranulação e liberação de fatores de crescimento, foi sugerido por Martínez-Lavin et al. ${ }^{(1)}$. Estudos anteriores de Matucci-Cerinic et al. têm reportado um aumento da atividade fibrinolítica em pacientes com afecção de pele e têm sugerido que o aumento da atividade do plasminogênio ativador funcionaria como um

Quadro 2 Classificação da osteoartropatia hipertrófica(1).

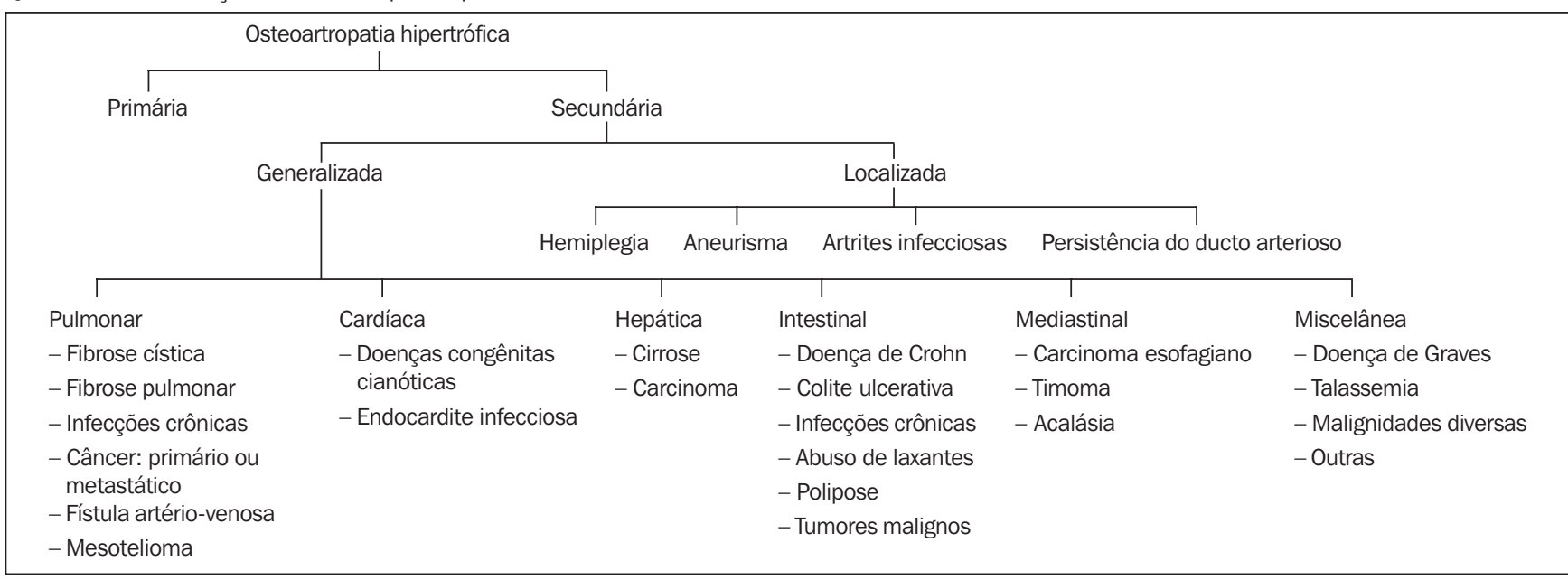


estímulo ao crescimento do tecido conjuntivo $^{(\mathbf{1 0})}$. Segundo Bianchi et al., uma alta concentração de receptores esteróides nucleares e ausência de receptores de fator de crescimento da epiderme podem indicar um comportamento específico do sistema receptor do fator de crescimento e esteróide na paquidermoperiostose $\mathrm{e}^{(\mathbf{1 1})}$. Outros autores reportam, em seus estudos, que a cultura de fibroblastos da pele afetada de pacientes com $\mathrm{OAH}$ primária produz uma maior quantidade de colágeno e alfa-1 procolágeno $^{(\mathbf{1 2})}$. No entanto, até o presente momento, apesar das várias propostas sugeridas para explicar a fisiopatogenia da $\mathrm{OAH}$, não há relatos ou dados conclusivos para explicar os achados clínicos dessa enfermidade.

Este trabalho relata um caso de um paciente com diagnóstico de $\mathrm{OAH}$ primária, com 15 anos de evolução, que apresentavadados clínicos e exames complementares que nos levaram ao diagnóstico dessa doença. O comprometimento articular predominava nos punhos, joelhos e tornozelos, com presença de sinovite (ocorre em $30 \%$ dos casos), além de outras características típicas dessa síndrome, já referidas na literatura $^{(13)}$.

Os exames laboratoriais estavam normais, como em casos já descritos em outros trabalhos ${ }^{(\mathbf{1 3})}$. O quadro radiológico, demonstrando caracteristicamente aumento da cortical e periostite de ossos longos, associado à clínica, reforçou nossa hipótese diagnóstica.

Outras condições, como osteoartropatia pulmonar hipertrófica, acromegalia, artropatia tireóidea, síndrome de Rosenthal-Kloepfer, artrite reumatóide (na fase inicial da $\mathrm{OAH}$ ), hanseníase, linfoma, leishmaniose difusa, leucemia, doença metastática, osteomielite crônica e doença de Paget, devem ser consideradas como diagnósticos diferenciais ${ }^{(\mathbf{2}, 3,6,14,15)}$.

$\mathrm{O}$ interesse deste relato é mostrar um caso de $\mathrm{OAH}$ primária com poliartralgia e sinovite crônica, raramente descrito na literatura, lembrando sempre de descartar as possíveis causas secundárias associadas a esta síndrome. Ela pode envolver, além dos ossos tubulares, a pelve e o crânio, sendo a coluna vertebral pouco atingida ${ }^{(\mathbf{1 6})}$.

\section{REFERÊNCIAS}

1. Martínez-Lavin M, Matucci-Cerinic M, Jajic I, Pineda C. Hypertrophic osteoarthropathy: consensus on its definition, classification, assessment and diagnostic criteria. J Rheumatol 1993;20:1386-7.

2. Souza BDB, Beltreschi F, Filho FSR, Carlquist I. Paquidermoperiostose: relato de caso. Rev Bras Reumatol 1985;25:209-10.

3. Cavichini QN, Brum AV, Monteiro RE, Anderson PAV, Vieira JTR. Colite ulcerativa associada a osteoartropatia hipertrófica. Rev Bras Colo-Proctol 1991;11:29-32.

4. Oikarinen A, Palatsi R, Kylmäniemi M, Keski-Oja J, Risteli J, Kallioinen M. Pachydermoperiostosis: analysis of the connective tissue abnormality in one family. J Am Acad Dermatol 1994;31:947-53.

5. Martínez-Lavin M, Pineda C, Valdez T, et al. Pri- mary hypertrophic osteoarthropathy. Semin Arthritis Rheum 1988;17:156-62.

6. Singh GR, Menon PSN. Pachydermoperiostosis in a 13 year-old boy presenting as an acromegaly-like syndrome. J Pediatr Endocrinol Metab 1995;8:514.

7. Inocêncio RM, Moreira HNC, Bertolo MB, Samara AM. Osteoartropatia hipertrófica primária (paquidermoperiostose): relato de dois casos e revisão da literatura. Rev Bras Reumatol 1992;32:34-40.

8. Ribeiro RC, Santos OLR, Moreira AM, Neto MPO. Paquidermoperiostose. J Bras Med 1993;64:4353.

9. Tay YK, Tham SN, Tey BH, Koay LH. Pachydermoperiostosis (idiopathic hypertrophic osteoarthropathy) - a case report and review. Ann Acad Med Singapore 1993;22:939-42.

10. Wegrowski Y, Gillery P, Serpier H, et al. Alteration of matrix macromolecule synthesis by fibroblasts from a patient with pachydermoperiostosis. J Invest Dermatol 1996;106:70-4.

11. Bianchi L, Lubrano C, Carrozzo AM, et al. Pachydermoperiostosis: study of epidermal growth factor and steroid receptors. Br J Dermatol 1995;132: 128-33.

12. Padula SJ, Broketa G, Sampieri A, et al. Increased collagen synthesis in skin fibroblasts from patients with primary hypertrophic osteoarthropathy. Evidence for transactivational regulation of collagen transcription. Arthrits Rheum 1994;37:1386-94.

13. Macedo LMG, Tormin FB, Gonçalves HAT, et al. Paquidermoperiostose: relato de um caso e revisão da literatura. Rev Bras Reumatol 1990;30:67-70.

14. Kirsner RS, Goodless D, Kerdel FA, Pardes JB, Falanga V. Enlargement of the hands and feet in a chronic smoker. Arthritis Rheum 1993;36:569-71.

15. Laredo Filho J, Lazzareschi M, Junior MBB, Kasinski S, Brizzi JJ. Paquidermoperiostose: atrofia hipertrófica primária - estudo de dois pacientes. Rev Imagem 1986;8:1-8.

16. Resnick D. Diagnosis of bone and joint disorders. 3rd ed. Philadelphia, PA: WB Saunders, 1995: 4421-6. 